\title{
Costs of Managing Patients with Diabetes in a Large Health Maintenance Organization in Israel: A Retrospective Cohort Study
}

\author{
Avi Porath · Naama Fund · Yasmin Maor
}

Received: September 24, 2016 / Published online: November 16, 2016

(C) The Author(s) 2016. This article is published with open access at Springerlink.com

\begin{abstract}
Introduction: The aim of this study was to evaluate the direct costs of patients with diabetes ensured in a large health maintenance organization, Maccabi Health Services (MHS), in order to compare the medical costs of these patients to the medical costs of other patients insured by MHS and to assess the impact of poorly controlled diabetes on medical costs.
\end{abstract}

Enhanced content To view enhanced content for this article go to http://www.medengine.com/Redeem/ D417F0600579CF91.

A. Porath

Maccabi Healthcare Services, Tel Aviv, Israel

A. Porath

Epidemiology Department, Faculty of Medicine, Ben-Gurion University of the Negev, Beer Sheva, Israel

N. Fund

Department of Health Services Research and Health Economics at Chief Physician Office of Maccabi Healthcare Services, Tel Aviv, Israel

Y. Maor $(\square)$

Infectious Disease Unit, Wolfson Medical Center, affiliated with Sackler Faculty of Medicine, Tel Aviv University, Holon, Israel

e-mail: Yasmin.maor@gmail.com
Methods: A retrospective analysis of patients insured in MHS during 2012 was performed. Data were extracted automatically from the electronic database. A glycated hemoglobin (HbA1c) level of $>9 \% \quad(75 \mathrm{mmol} / \mathrm{mol})$ was considered to define poorly controlled diabetes, and that of $<7 \%(53 \mathrm{mmol} / \mathrm{mol})$ and $<8 \% \quad(64 \mathrm{mmol} / \mathrm{mol})$ to define controlled diabetes for patients aged $<75$ and $\geq 75$ years, respectively. Multivariate analysis analyses were done to assess factors affecting cost.

Results: Data on a total of 99,017 patients with diabetes were obtained from the MHS database for 2012. Of these, $54 \%$ were male and $72 \%$ were aged $45-75$ years. The median annual cost of treating diabetes was 4420 cost units (CU), with hospitalization accounting for $56 \%$ of the total costs. The median annual cost per patient in the age groups $35-44$ and $75-84$ years was $2836 \mathrm{CU}$ and $7033 \mathrm{CU}$, respectively. Differences between costs for patients with diabetes and those for patients without diabetes was $85 \%$ for the age group $45-54$ years but only $24 \%$ for the age group 75-84 years. Medical costs increased similarly with age for patients with controlled diabetes and those with poorly controlled diabetes costs, as did additional co-morbidities. 
Costs were significantly impacted by kidney disease. The costs for patients with an HbA1c level of $8.0-8.99 \% \quad(64-74 \mathrm{mmol} / \mathrm{mol})$ and 9.0-9.99\% (75-85 mmol/mol) were 5722 and $5700 \mathrm{CU}$, respectively. In a multivariate analysis the factors affecting all patients' costs were HbA1C level, male gender, chronic diseases, complications of diabetes, disease duration, and stage of kidney function.

Conclusions: The direct medical costs of patients with diabetes were significantly higher than those of patients without diabetes. The main drivers of these higher costs were hospitalizations and renal function. In poorly controlled patients the effect of HbA1c on costs was limited. These findings suggest that it is cost effective to identify patients with diabetes early in the course of the disease.

Funding: The work was sponsored by internal funds of the authors. Article processing charges for this study was funded by Novo Nordisk.

Keywords: Chronic renal failure; Costs; HbA1c; Type 2 diabetes

\section{INTRODUCTION}

Diabetes is one of the most commonly occurring diseases in both developed countries and in middle- and low-income countries. According to the International's Diabetes Federation Diabetes Atlas [1, 2], during 2014 there were 387 million people living with diabetes worldwide. One in 12 people around the globe suffers from diabetes, and $50 \%$ of afflicted patients are unaware of their disease status. During 2014 there were 4.9 million deaths from diabetes. According to the Israeli Quality Indicators Program for Community Health [3, 4], in 2013 there were 468,103 people aged 18 years or older $(9.6 \%$ of the adult Israeli population) diagnosed with diabetes in Israel. In Israel as in other countries in the world, there is documented evidence that the prevalence of diabetes is on the rise. This increase was particularly alarming in 2011 and 2012, with the Israeli diabetes rate increased from $9.1 \%$ of adults in 2011 to $9.5 \%$ in 2012. The risk of diabetes increases with age, reaching a peak in the age group of 75-84 years. Only $64.3 \%$ of diabetes patients have controlled diabetes, defined as a glycated hemoglobin (HbA1c) level of $>7 \%(53 \mathrm{mmol} / \mathrm{mol})$ in the age group 18-75 years and an HbA1C level of $>8 \%(64 \mathrm{mmol} / \mathrm{mol})$ in the age group of 75 years and older. Of those individuals diagnosed with diabetes, $31.6 \%$ have renal injury (proteinuria or increased creatinine).

These numbers reflect the growing economic burden on healthcare providers due to diabetes. A recent systematic review of the global evidence on the costs of type 2 diabetes demonstrated that the costs of treating diabetes increase over time and with disease severity. Direct costs were found to be higher than indirect costs and to be particularly high in Western countries, such as the USA [2]. A Canadian study demonstrated that costs were particularly high after the first year of diagnosing diabetes and reached C\$3785-3826 (Canadian dollars). These costs increased substantially for older patients and for patients who eventually died during the follow-up. After accounting for baseline co-morbidities, costs were primarily incurred through inpatient acute hospitalizations, physician visits, prescription medications, and assistive devices [5]. Similar results have been found in other countries, including the USA and Europe [6-11].

In order to decrease costs and improve patients' outcomes it is important to understand the different effects of co-morbidities, complication, and various 
interventions on the costs of treating patients with diabetes. For example, chronic renal injury significantly raises the costs of treating patients with diabetes [12-14]. Also, it is important to assess the relative impact of higher HbA1C levels on medical costs as this guides the choice of cost-effective interventions in the spectrum of diabetic patients failing to achieve their HbA1c goals.

Maccabi Healthcare Services (MHS) is the second largest primary healthcare insurer and provider in Israel. This health maintenance organization (HMO) serves $25 \%$ of the total population in Israel, with approximately 2 million members. In a study assessing diabetes mellitus costs in MHS, diabetes accounted for $3.5 \%$ of the total medical costs for both men and women [15].

The aim of this study was to evaluate the direct costs of patients with diabetes ensured by MHS in order to compare the medical costs of these patients to those of other patients insured by MHS and to identify the drivers of these costs. In particular, we wanted to assess the impact of poorly controlled diabetes on medical costs as the Israeli Ministry of Health and the National Quality Indicator Program pay particular attention to patients with poorly controlled diabetes, defined as an HbA1c level of $>9 \%(75 \mathrm{mmol} / \mathrm{mol})[3,4]$. To do so we used patient data complied in the electronic MHS diabetes registry which contains information on approximately 100,000 Israeli patients with diabetes.

\section{METHODS}

\section{Setting}

This retrospective study was conducted by MHS after obtaining approval from the ethics committee of MSH. It was performed in accordance with the Helsinki Declaration. This article does not contain any new studies with human or animal subjects performed by any of the authors. Since 1997, information on member-MSH interactions (i.e., diagnoses, visits to primary and secondary care physicians, visits to outpatient clinics, hospitalizations, laboratory tests, and purchased and dispensed medications) have been recorded in a large central computerized database. Data on patients' interactions with MHS can be retrieved from this database. The database includes information on hospitalizations, emergency department visits, physician visits, outpatient specialist visits, home healthcare visits, purchases of medications and other aids, laboratory tests, imaging, and paramedical services such as nursing care, physiotherapy, social workers, and dietary consultations. Each individual has a unique identification code in the system that is valid for all encounters. All medical services have a price tag that can be used to estimate costs related to each patient or encounter. Information on patients' out of pocket expenses, services that are fully paid for by the patients themselves, and treatments provided directly by the state, such as primarily certain mental healthcare services (e.g., hospitalization in psychiatric wards) and costs of a hospital delivery, are also not complied in the database. Indirect costs, such as productivity losses owing to sick leave and early retirement are also not included. Services are automatically converted into monetary terms by the MHS' Financial Department [16]. To avoid disclosure of internal corporate information, for this study all costs were translated into internal resource cost units $(\mathrm{CU})$. CU were calculated as the actual cost corrected to the formal pricing of medicines and health technologies in Israel. 
The database includes several automatically formulated registries, including a diabetes registry. Patients are identified by an automated database search; consequently, the registry is not dependent on physicians actively reporting on the patient to the registry. These registries are routinely validated by community physicians and other healthcare workers. To be included in the Diabetes registry patients had to have one or more of the following criteria. The patient has to be defined as diabetic according to the criteria suggested by American Diabetes Association: (1) presence of symptoms leading to a diagnosis of diabetes; (2) a fasting plasma glucose concentration of $>126 \mathrm{mg} / \mathrm{dl}$ $(7.0 \mathrm{mmol} / \mathrm{l})$ or casual (namely, any time of day without regard to time since last meal) plasma glucose concentration of $200 \mathrm{mg} / \mathrm{dl}$ $(11.1 \mathrm{mmol} / \mathrm{l})$. In order to reach maximal validity, we also included any patient who met one of the following criteria: (1) purchased at least two hypoglycemic medications or a single insulin dose during one 6-month period; (2) had an HbA1c measurement of at least $7.25 \%(55.7 \mathrm{mmol} / \mathrm{mol})$. An HbA1c level of $6.5 \% \quad(47.5 \mathrm{mmol} / \mathrm{mol})$ was used as entry criterion to the registry only when the patient had been previously diagnosed as diabetic. The codes employed do not distinguish between insulin-dependent diabetes mellitus (type 1) and non-insulin-dependent diabetes mellitus (type 2). According to the 1994 Israel National Health Act, MHS may not deny coverage to applicants on any grounds, including age or state of health. Thus, all sectors of the Israeli population are represented in MHS, except for young adults aged 18-21 years who, due to a high percentage of them being enlisted in the Israeli Defence Forces, are provided medical care from this latter source.

\section{Patients}

To be included in these analyses patients had to registered in the diabetes registry of MSH during 2012. Data extracted from the registry included sociodemographic details, duration of diabetes, drugs prescribed to treat diabetes, comorbidities, HbA1c level, renal function, and proteinuria. Patients were considered to have poorly controlled diabetes if the HbA1c level was $>9 \% \quad(75 \mathrm{mmol} / \mathrm{mol})$. Controlled diabetes was defined as an HbA1c level of $<7 \%$ (53 mmol/mol) for patients aged $<75$ years and an $\mathrm{HbA1c}$ level of $<8 \%(64 \mathrm{mmol} / \mathrm{mol})$ for patients aged $\geq 75$ years within the past year.

\section{Statistical Methods}

Patient data were analyzed using descriptive statistics and expressed. Continuous variables were expressed as the mean and standard deviation and dichotomous variables as the number and percentage. Statistical significance was set at $p<0.05$.

To assess determinants of costs, we performed both a univariate and multivariate analysis. The dependent variable was patient costs. Candidate dependent variables were age, gender, diabetes duration, HbA1c level, number of co-morbidities, renal injury, and medications. To enter a variable into the multivariate regression model $p$ was set at $<0.2$. Significance was set at $p<0.05$. All analyses were conducted using standard statistical software (SPSS ver. 22; IBM Corp., Armonk, NY).

\section{RESULTS}

The diabetes registry included 99,017 patients, of whom $54 \%(53,283)$ were male and $72 \%$ were in the age group of $45-75$ years. The mean and 
median costs of treating a patient with diabetes for 1 year was 14,250 and $4420 \mathrm{CU}$, respectively. The main driver of cost was hospitalization, which accounted for $56 \%$ of the total spending on patients with diabetes. Additional costs included physician fees (11\%) and all medications for treating diabetes (16\%). The median annual medical costs for men and women were 4046 and $4839 \mathrm{CU}$, respectively. Costs increased significantly with age (Fig. 1). For patients aged 35-44 years, the annual cost per patient was $2836 \mathrm{CU}$ as compared to 7033 CU for patients aged 75-84 years. Costs for patients aged 25-34 years was 3315 CU per year. The costs significantly increased with longer period of time of diabetes diagnosis (Fig. 2), with the costs of patients diagnosed within the past 3 years being $3309 \mathrm{CU}$ compared to 7975 $\mathrm{CU}$ for patients diagnosed $>14$ years ago. As can be seen in Fig. 3, the differences between the costs of patients with diabetes and the annual median costs of all members in MHS decreased with increasing age, with the difference being $86 \%$ for patients aged $45-54$ years but only $14 \%$ for patients aged 75-84 years.

To assess cost attributes in patients with poor control of their diabetes we assessed various cost attributes in patients with an HbA1c level of

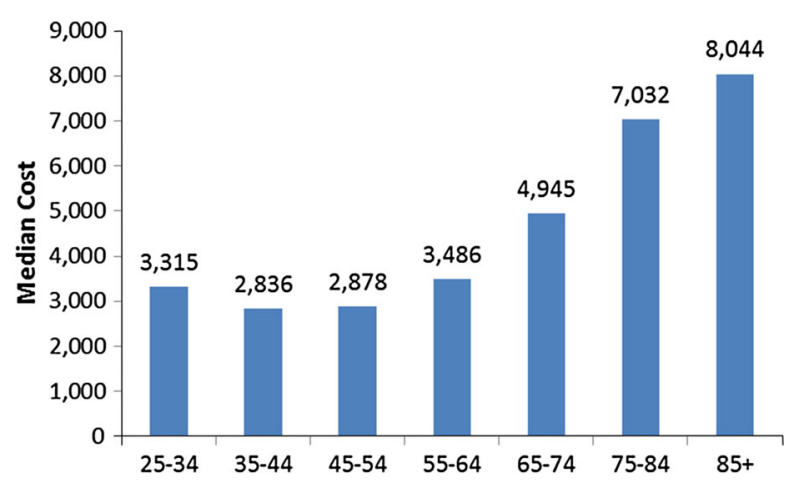

Fig. 1 Median annual cost (in cost units (CU)] per patient with diabetes by age distribution (in years). Numbers at top of each bar Number of patients

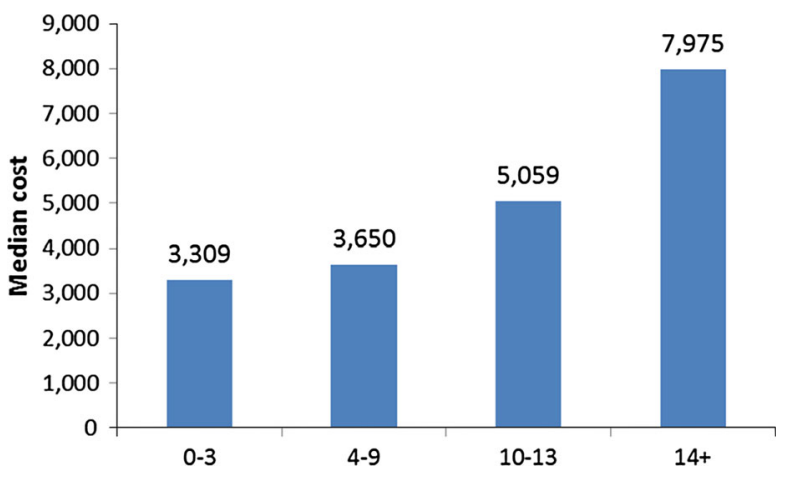

Fig. 2 Median costs (in CU) of patients with diabetes in relation to length of diabetes diagnosis (in years). Numbers at top of each bar Number of patients

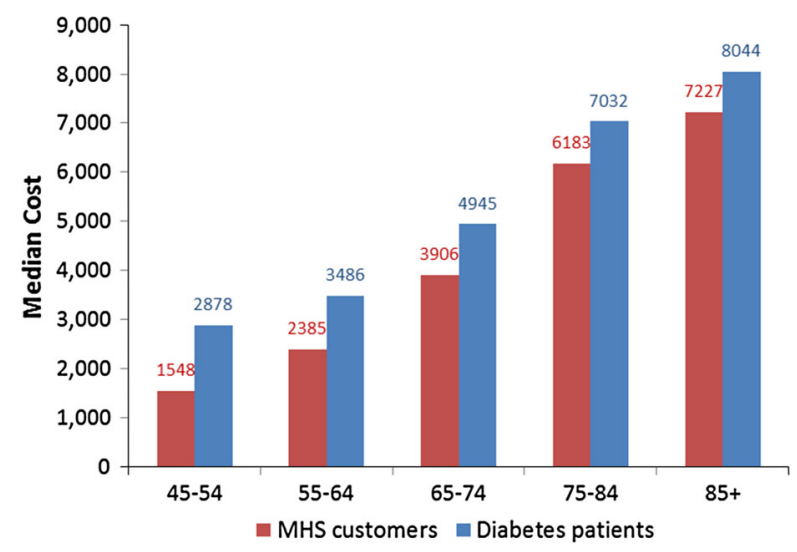

Fig. 3 Comparison of median costs (in CU) of patients with diabetes to median costs of all customers of Maccabi Healthcare Services clients by age (in years). Numbers at top of each bar Number of patients

$>9 \%$ (75 mmol $/ \mathrm{mol})$ compared to patients with an HbA1c level of $<7 \%(53 \mathrm{mmol} / \mathrm{mol})$ for patients aged $<75$ years and with an HbA1c level of $<8 \%(64 \mathrm{mmol} / \mathrm{mol})$ for patients aged $\geq 75$ years in the past year. As demonstrated in Table 1, costs for both patients with controlled diabetes and poorly controlled diabetes increased by age in a similar fashion. Additional co-morbidity increased costs in both groups, but this variable was more significant in patients with poorly controlled diabetes. In patients with poorly controlled diabetes, the median costs for those with no 
Table 1 Comparing costs of patients with controlled and poorly controlled diabetes by age group

\begin{tabular}{lccll}
\hline $\begin{array}{l}\text { Age } \\
\text { (years) }\end{array}$ & $\begin{array}{l}\text { Number of patients } \\
\text { with poorly controlled } \\
\text { diabetes (\%) }\end{array}$ & $\begin{array}{l}\text { Mean costs } \\
(\mathbf{C U})^{\mathbf{a}}\end{array}$ & $\begin{array}{l}\text { Median costs of patients } \\
\text { with poorly controlled } \\
\text { diabetes (CU) }\end{array}$ & $\begin{array}{l}\text { Median costs of patients } \\
\text { with controlled } \\
\text { diabetes (CU) }\end{array}$ \\
\hline $15-24$ & $9(0.1)$ & $5075(7221)$ & 2107 & 2684 \\
$25-34$ & $114(1.3)$ & $6138(8791)$ & 2568 & 3705 \\
$35-44$ & $950(10.4)$ & $7538(14016)$ & 3732 & 3028 \\
$45-54$ & $2357(25.9)$ & $10,792(25.555)$ & 4202 & 2954 \\
$55-64$ & $3029(33.2)$ & $13,626(34,874)$ & 5266 & 3493 \\
$65-74$ & $1677(18.4)$ & $15,603(26,930)$ & 6992 & 4899 \\
$75-84$ & $766(8.4)$ & $22,794(35,435)$ & 10,017 & 6796 \\
$85+$ & $211(2.3)$ & $24,749(35,618)$ & 11,669 & 7783 \\
\hline
\end{tabular}

$C U$ Cost unit, $S D$ standard deviation

a Standard deviation (SD) is given in parenthesis

co-morbidity, one co-morbidity, two co-morbidities, and three or more co-morbidities were 3240, 3716, 5130 and $11,555 \mathrm{CU}$, respectively; in comparison, in patients with controlled diabetes, the respective median costs were 2726, 3305, 4146, and $8170 \mathrm{CU}$. Surprisingly, HbA1c per se had less effect than co-morbidity on patients' costs, as seen in Table 2 .

Kidney injury and kidney disease increased significantly with age (Fig. 4). Costs were significantly impacted by kidney disease, particularly in patients with kidney injury stage C and D (Fig. 5). Hospitalization was the major contributor to costs in all stages of kidney impairment, representing $53 \%$ of costs in stage A, $60 \%$ in stage B, $66 \%$ in stage C, and $70 \%$ in stage D.

In a multivariate regression model we assessed the contribution of various patient factors to costs. The independent factor was patient costs per year. Factors that significantly affected patients' costs were HbA1C level, male gender, any chronic disease, diabetes complications, disease duration, and kidney function stage. $R^{2}$ was $17.2 \%$.

\section{DISCUSSION}

In this analysis we assessed the cost of treating patients with diabetes registered in a large Maccabi Health Services database in Israel in an attempt to understand the drivers of costs. Our results demonstrate that MHS expenditure was $86 \%$ higher in younger patients with diabetes (age range $45-54$ years) than in other MHS clients. Differences in expenditure were less striking with increasing patient age. These results are in agreement with those of other studies which demonstrated increased costs incurred in treating patients with diabetes [17-21]. A study assessing the economic burden of diabetes in the USA in 2012 found that patients with diabetes had 2.3-fold higher medical expenditures than expenditures expected in the absence of diabetes, with inpatient care accounting for $43 \%$ of the increased expenditure [17]. Chang et al. [18] 
Table 2 Patients costs in relation to glycated hemoglobin levels

\begin{tabular}{lcll}
\hline HbA1c (\%) & Number of patients & Mean cost $(\mathbf{C U})^{\mathbf{b}}$ & Median cost (CU) \\
\hline $5.0-5.99[31-41]$ & 7935 & $16,206(39,107)$ & 4615 \\
$6.0-6.99[42-52]$ & 40,767 & $10,921(25,414)$ & 4095 \\
$7.0-7.99[53-63]$ & 22,479 & $12,237(26,928)$ & 4724 \\
$8.0-8.99[64-74]$ & 9040 & $14,242(29,225)$ & 5722 \\
$9.0-9.99[75-85]$ & 4338 & $13,654(25,718)$ & 5700 \\
$10.0-10.99[85-95]$ & 2289 & $13,068(28,539)$ & 5039 \\
$11.0-11.99[96-106]$ & 1279 & $13,856(28,241)$ & 5197 \\
$\geq 12.0[\geq 107]$ & 1207 & $13,754(43,342)$ & 4348 \\
\hline
\end{tabular}

HbA1c Glycated hemoglobin

a HbAlc level in millimole/mole is given in square brackets

b $\mathrm{SD}$ in given in parenthesis

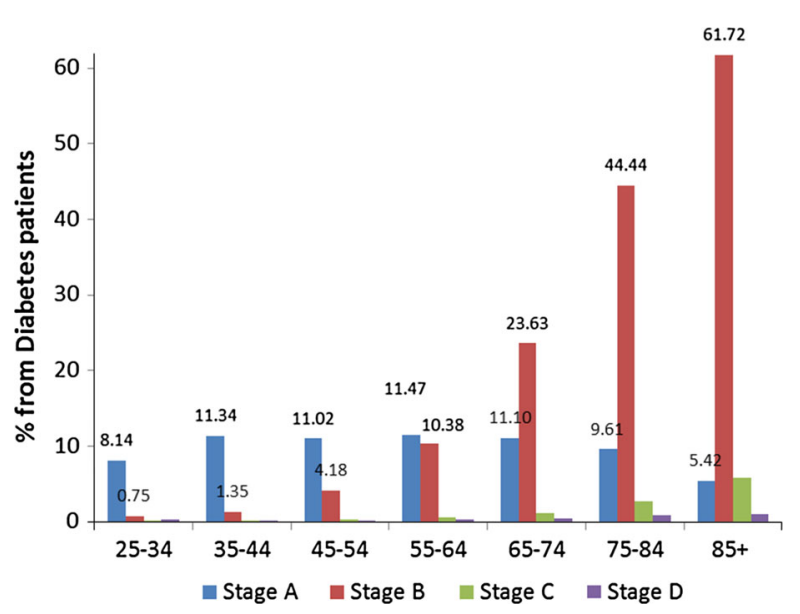

Fig. 4 Kidney injury by age (in years)

demonstrated that in Taiwan, where all patients receive primary care through a national health care system, patients with diabetes have 1.4-fold higher medical costs than patients without diabetes. These authors also reported that in 2009, the medical costs of outpatient management of diabetes accounted for $18.5 \%$ of all outpatient expenditures. Similar to our results, the cost of patients with micro- and macrovascular complications was fourfold higher than that of patients who did not have complications associated with

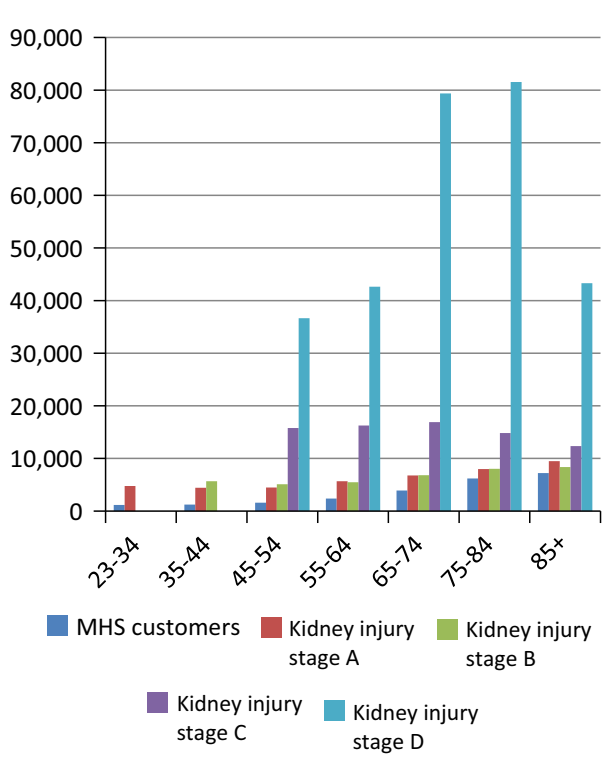

Fig. 5 Medical costs (in CU; Y-axis of diabetes patients with kidney injury stages $\mathrm{A}, \mathrm{B}, \mathrm{C}$, and D registered in the Maccabi Healthcare Services (MHS) database compared to all Maccabi Healthcare Services (MHS) customers by age (in years, $X$-axis)

diabetes [18]. In a study assessing medical costs of patients with diabetes in Spain, the medical care costs of patients with diabetes were $72.4 \%$ higher than those for patients without diabetes [19]. Based on patient data compiled in this Spanish database, hospitalization of patients 
with diabetes accounted for $41.9 \%$ of the total costs, generating a difference of $70 \%$ between patients with diabetes and patients without diabetes.

We demonstrated a significant impact of co-morbidities on the medical costs of patients with diabetes. Costs increased by threefold in patients with diabetes with three co-morbidities compared to patients with no co-morbidities in well-controlled patients with diabetes. The increase was 3.6-fold higher in patients with uncontrolled diabetes. These results are comparable to data from reported from other countries [9, 10, 13, 17, 20-22].

Several factors emerged as main drivers of cost in patients with diabetes, including HbA1C level, male gender, any additional chronic disease, complications associated with diabetes, duration of diabetes, and kidney function stage. In particular, the effect of decreased renal function, proteinuria, and dialysis were significant drivers of expenditures that greatly surpassed the effect of HbA1C level. Surprisingly, poorly controlled diabetes had a lesser effect than expected on patients' costs. Menzin et al. [23] performed a retrospective cohort study and found that the odds of having at least one diabetes-related hospitalization were not significantly associated with higher mean HbA1c levelwith the exception of patients with a mean HbA1c level of $\geq 10 \% \quad(85.8 \mathrm{mmol} / \mathrm{mol})$. However, higher mean HbA1c levels were associated with significantly higher estimated hospitalization costs. The basic assumption is that targeting this particular population of very poorly controlled diabetes patients with a HbA1c level of $\geq 9 \% \quad(75 \mathrm{mmol} / \mathrm{mol}) \quad$ is cost-effective, whereas our data may suggest that this is not necessarily so.

In our study population even a mild decrease in renal function (defined as stage A) resulted in a significant increase in a patient's medical care costs. This was true for all age groups. Costs were much higher when the renal impairment was defined as stage C and D. Ward et al. [7] estimated that the event costs of proteinuria and microalbuminuria were relatively low-cost interventions ( $\$ 109$ and $\$ 79$, respectively) while end-stage renal disease cost $\$ 71,714$. It has also been demonstrated that medical costs increase significantly for patients who progress from stage A and B kidney impairment to stage C and D [14]. However, our data appear to suggest that even stage A renal impairment is a marker of patients who are costly to the system beyond the expected cost of diabetes or proteinuria per se.

Kidney deterioration may be prevented not only by decreasing HbA1c level but also by other interventions, such as better control of blood pressure, improving patients' lipid profiles, use of aspirin, smoking cessation, and physical activity [24-27]. This may explain why cost assessment goes beyond the decrease of HbA1c level. Identifying these patients in an early stage and implementing multifaceted programs intervening in kidney function decline may offer a significant cost-effective intervention for patients with diabetes. This benefit seems to be pronounced in the younger population, as these patients are expected to remain in MHS for many additional years, with each year contributing to increased costs. Further study is warranted in this area.

The study has several limitations. This was a retrospective observational study. Therefore, all information relied on the completeness of the medical records of routine clinical visits. Clinical events may not have been captured in full. It is possible that some co-morbidities were not recorded and that laboratory data were missing at various time-points. 


\section{CONCLUSION}

The results of this study show that direct costs of patients with diabetes insured by MHS are higher than the costs of patients without diabetes insured by MHS. The major attributes of costs were hospitalizations and renal disease. In poorly controlled patients [HbA1c 8.0-8.99\% (64-74 mmol/mol) and patients with HbA1c $>9.0 \%(75 \mathrm{mmol} / \mathrm{mol})]$ the effect of $\mathrm{HbA} 1 \mathrm{c}$ level on costs was limited. These findings suggest that it is cost effective to identify patients with diabetes early in the course of the disease and to direct efforts at preventing renal deterioration and hospitalizations.

\section{ACKNOWLEDGEMENTS}

The work was sponsored by internal funds of the authors. Article processing charges for this study were funded by Novo Nordisk (Bagsværd, Denmark). All named authors meet the International Committee of Medical Journal Editors (ICMJE) criteria for authorship for this manuscript, take responsibility for the integrity of the work as a whole, and have given final approval for the version to be published.

Disclosures. Y. Maor has been paid for consultancy services by Novo Nordisk. A. Porath and N. Fund declare that they have nothing to disclose.

Compliance with Ethics. The study was approved by the ethics committe of Maccabi Healthcare Servies and was performed in accordance with the Helsinki Declaration. This article does not contain any new studies with human or animal subjects performed by any of the authors.
Data Availability. The datasets analyzed during the current study are available from the corresponding author upon reasonable request.

Open Access. This article is distributed under the terms of the Creative Commons Attribution-NonCommercial 4.0 International License (http://creativecommons.org/licenses/ by-nc/4.0/), which permits any noncommercial use, distribution, and reproduction in any medium, provided you give appropriate credit to the original author(s) and the source, provide a link to the Creative Commons license, and indicate if changes were made.

\section{REFERENCES}

1. International Diabetes Federation Diabetes Atlas, 6th edn. https://www.idf.org/diabetesatlas.

2. Seuring T, Archangelidi O, Suhrcke M. The economic costs of type 2 diabetes: a global systematic review. Pharmaco Econ. 2015;33:811-31.

3. Manor O, Shmueli A, Ben Yehuda A, Paltiel O, Kalderon R. The National Program for Quality Indicators in Community Health Care. The Israel National Institution for Health Policy and Health Services Research, Tel Hashomer. December 2014.

4. Manor O, Shmueli A, Ben-Yehuda A, Paltiel O, Calderon R, Jaffe DH. National Program for Quality Indicators in Community Healthcare in Israel Report, 2008-2010. Jerusalem, Israel: School of Public Health and Community Medicine, Hebrew University-Hadassah; 2012.

5. Rosella LC, Lebenbaum M, Fitzpatrick $\mathrm{T}$, et al. Health economics impact of diabetes on healthcare costs in a population-based cohort: a cost analysis. Diabet Med 2016;33(3):395-403.

6. Sabalea U, Bodegårda $\mathrm{J}$, Sundströmbet $\mathrm{J}$, et al. Healthcare utilization and costs following newly diagnosed type- 2 diabetes in Sweden: A follow-up of 38,956 patients in a clinical practice setting. Primary Care Diabetes. 2015;9:330-7.

7. Ward A, Alvarez P, Vo L, Martin S. Direct medical costs of complications of diabetes in the United 
States: estimates for event-year and annual state costs (USD 2012). J Med Econ. 2014;17:176-83.

8. Huber CA, Schwenkglenks M, Rapold R, Reich O. Epidemiology and costs of diabetes mellitus in Switzerland: an analysis of health care claims data, 2006 and 2011. BMC Endocrine Disord. 2014;14:44.

9. Jacob L, von Vultee C, Kostev K. Prescription patterns and the cost of antihyperglycemic drugs in patients with type 2 diabetes mellitus in Germany J Diabetes Sci Technol. doi:10.1177/ 1932296816658746.

10. Sancho-Mestre C, Vivas-Consuelo D, Alvis-Estrada L, Romero M, Usó-Talamantes R, Caballer-Tarazona V. Pharmaceutical cost and multimorbidity with type 2 diabetes mellitus using electronic health record data. BMC Health Serv Res. 2016;16(1):394.

11. Migdalis I, Rombopoulos G, Hatzikou M, Manes C, Kypraios N, Tentolouris N. The cost of managing type 2 diabetes mellitus in Greece: a retrospective analysis of 10-year patient level data "The HERCULES Study". Int J Endocrinol. 2015;2015:520759.

12. Huber CA, Diem P, Schwenkglenks M, Rapold Reich O. Estimating the prevalence of comorbid conditions and their effect on health care costs in patients with diabetes mellitus in Switzerland. Diabet Metabolic Syn Obes. 2014;7:455-65.

13. Salas M, Hughes D, Zuluaga A, Vardeva K, Lebmeier M. Costs of medication nonadherence in patients with diabetes mellitus: a systematic review and critical analysis of the literature. Value Health. 2009; 12:915-22.

14. Vupputuri S, Kimes TM, Calloway MO, Christian JB, Bruhn D, Martin AA, Nichols GA. The economic burden of progressive chronic kidney disease among patients with type 2 diabetes. J Diabet Compl. 2014;28:10-6.

15. Chodick G, Porath A, Alapia H, Sella T, Flasha S, Wooda F, Shalev V. The direct medical cost of cardiovascular diseases, hypertension, diabetes, cancer, pregnancy and female infertility in a large HMO in Israel. Health Policy. 2010;95(2-3):271-6.

16. Heymann A, Chodick G, Halkin H, Kokia E, Shalev V. Description of a diabetes disease register extracted from a central database. Harefuah. 2007;146:15-7.

17. American Diabetes Association. Economic costs of diabetes in the U.S. in 2012. Diabetes Care. 2013;36:1033-46.

18. Chang TJ, Jiang YD, Chang $\mathrm{CH}$, Chung $\mathrm{CH}$, Yu NC, Chuang LM. Accountability, utilization and providers for diabetes management in Taiwan, 2000e2009: An analysis of the National Health Insurance database. J Formosan Med Assoc. 2012;111:605-16.

19. Mata-Cases M, Casajuana M, Franch-Nadal J, et al. Direct medical costs attributable to type 2 diabetes mellitus: a population-based study in Catalonia, Spain. Eur J Health Econ. 2016;17(8):1001-10.

20. Li R, Bilik D, Brown MB, Zhang P, Ettner SL, Ackermann RT, Crosson JC, Herman WH. Medical costs associated with type 2 diabetes complications and comorbidities. Am J Manag Care. 2013;19(5):421-30.

21. Bruno G, Picariello R, Petrelli A, Panero F, Costa G, Cavallo-Perin P, Demaria M, Gnavi R. Direct costs in diabetic and non-diabetic people: the population-based Turin study, Italy. Nutr Metab Cardiovasc Dis. 2012;22:684-90.

22. Bron $\mathrm{M}$, Guerin A, Latremouille-Viau D, Ionescu-Ittu R, Viswanathan P, Lopez C, Wu EQ. Distribution and drivers of costs in type 2 diabetes mellitus treated with oral hypoglycemic agents: a retrospective claims data analysis. J Med Econ. 2014;17(9):646-57.

23. Menzin J, Korn JR, Cohen J, Lobo F, Zhang B, Friedman M, Neumann PJ. Relationship between glycemic control and diabetes-related hospital costs in patients with type 1 or type 2 diabetes mellitus. J Manag Care Pharm. 2010;16(4):264-75.

24. Van Buren PN, Toto RD. The pathogenesis and management of hypertension in diabetic kidney disease. Med Clin North Am. 2013;97(1):31-51.

25. Koufaki P, Greenwood SA, Macdougall IC, Mercer TH. Exercise therapy in individuals with chronic kidney disease: a systematic review and synthesis of the research evidence. Annu Rev Nurs Res. 2013;31:235-75.

26. Narita T, Kakei M, Ito S. Aggressive antihypertensive treatment and serum lipid lowering therapy are necessary to prevent deterioration of the renal function even in elderly type 2 diabetic patients with persistent albuminuria. Gerontology. 2002;48(5):302-8.

27. Palmer AJ, Valentine WJ, Chen R, Mehin N, Gabriel S, Bregman B, Rodby RA. A health economic analysis of screening and optimal treatment of nephropathy in patients with type 2diabetes and hypertension in the USA. Nephrol Dial Transplant. 2008;23(4):1216-23. 